\title{
A PHARMACOLOGIC AND CLINICAL STUDY OF PAPAVERIN *
}

\author{
DAVID I. MACHT, M.D. \\ BALTIMORE
}

Papaverin is one of the principal primary opium alkaloids in point of both quantity and pharmacologic interest. Its amount in opium varies from $0.1^{1}$ to $0.2^{2}$ per cent. The alkaloid was discovered by Merck in 1848 . It crystallizes in white prisms, with a melting point of $147 \mathrm{C}$. The crystals are insoluble in water and alkalis, difficultly soluble in ether and benzol, but easily soluble in warm alcohol, chloroform and acetone. It is tasteless, is neutral in reaction with litmus and is polariscopically inactive. The alkaloid easily combines with acids, forming salts, and it is the sulphate and more especially the hydrochlorid that are chiefly used in physiologic work. These salts can be obtained on the market in a very pure chemical state, and are soluble in water and in normal saline. Like all the other opium alkaloids, papaverin is characterized by color reactions by which it can be identified and distingtuished from the others. These color reactions have been recently well described by Warren. ${ }^{3}$ The most characteristic are the deep rose color produced by Marquis' reagent (sulphuric acid plus formaldehyd) and the greenish-blue color produced by potassium ferricyanid and Marquis' reagent. ${ }^{4}$

The empirical formula for papaverin is $\mathrm{C}_{20} \mathrm{H}_{21} \mathrm{NO}_{4}$. Its chemical structure has been thoroughly worked out and is of great interest, not only in itself, but also as throwing light on the constitution of other opium alkaloids. A thorough analysis of its constitution finally enabled Pictet and Gams; to prepare it synthetically. Papaverin belongs to the so-called benzyl-isoquinolin group of opium alkaloids, ${ }^{6}$

\footnotetext{
* Submitted for publication, March 27, 1916.

* From the Departments of Pharmacology and Medicine, Johns Hopkins University.

1. Simon: Dissertation, Bern, 1903.

2. Henry: The Plant Alkaloids, 1913.

3. Warren: Am. Jour. Pharm., 1915, 1xxxvii, 439.

4. Warren: Jour. Am. Chem. Soc., 1915, xxxvii, 2402.

5. Pictet and Gams: Beitr. z. Klin. d. Tuberk., xlii, 2943.

6. Winterstein and Trier: Die Alkaloide, 1910, p. 160.
} 
the principal other constituent of which is narcotin. Its complete structural formula is as follows:

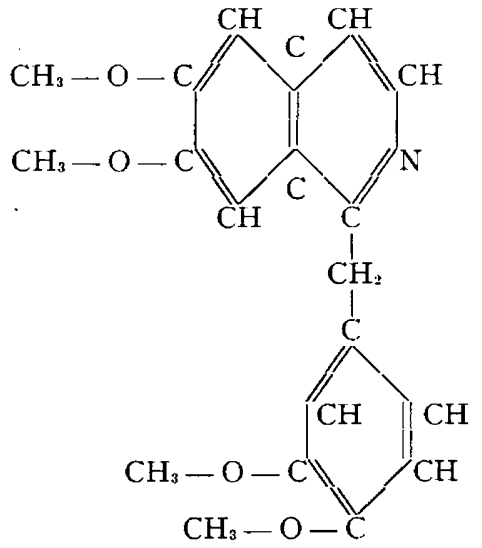

\section{Pharmacology}

The earlier pharmacologic experiences with papaverin are very few and limited. We need consider only the works of Claude Bernard and Baxt. Claude Bernard ${ }^{7}$ denied to papaverin any narcotic properties, and classed it as a convulsant closely related to thebain. This view, which is a rather exceptional one, is as remarkable as the same author's attribution of powerful narcotic properties to the comparatively inert narcein. Sichting ${ }^{8}$ from observations on himself and other human subjects concluded that papaverin is a mild narcotic. The most important and comprehensive of the earlier works on papaverin is that by Baxt. ${ }^{9}$ Basing his conclusions on many animal experiments, Baxt claimed that papaverin is possessed of marked narcotic properties and is but slightly toxic for higher animals. The same author also called attention to its effect upon the frog's heart. Von Schroeder, ${ }^{10}$ in his classic paper on the opium alkaloids, takes stand midway between Clatude Barnard and Baxt, attributing to papaverin mild narcotic properties and also calling attention to the slowing of the frog's heart after injection of the drug. It is surprising to note that he failed to observe a fall in blood pressure, which is one of its striking characteristics.

Of the recent works on papaverin, by far the most important has been done by Pal of Vienna ${ }^{11}$ and his school. To Pal belongs the

7. Cl. Bernard: Compt. rend. Acad. d. sc.. lix, 464.

8. Sichting: Dissertation, Bonn, 1869.

9. Baxt: Arch. f. Anat. w. Physiol., 1869, p. 112.

10. Von Schroeder: Arch. f. Exper. Path. u. Pharmakol., 1883, xvii, 96.

11. Pa1: Deutsch. med. Wchnschr., 1913, pp. 395, 2068, 2514; Wien med. Wchnschr., 1913, p. 1049 ; Zentralbl. f. Physiol., 1902, p. 68. 
credit especially of calling attention to the action of papaverin on smooth muscle. It is strange to note, however, that although Pal has written much on the subject and tried the drug extensively in the clinic. he has published, with the exception of his work on the intestinal muscle, very few experimental data on the subject.

A more careful pharmacologic study of papaverin by the most modern methods was desirable, and it was undertaken by the present author in connection with a general study of the opium alkaloids individually and in combination with each other. The results were so interesting and so fraught with therapentic possibilities, that it is deemed well to describe the pharmacology of papaverin with a few clinical experiences in a separate paper.

The most important pharmacologic properties of papaverin may be considered under four headings-its effect on the circulation, its effect on the respiration, its analgesic effect, and its action on smooth muscle structures.

\section{A. ACTION ON CIRCULATION}

Effect on the Heart.-If we excise a frog's heart and perfuse it with a weak solution of papaverin hydrochlorid $(0.001$ per cent. or less) in physiologic saline solution, a distinct slowing of the heart beat is noted, together with an increase in the toxicity of the heart muscle and more powerful contractions. If a stronger solution of papaverin is used (0.01 to 0.1 per cent.), the stimulating action is absent, and instead, a greater slowing of the beat and relaxation of the heart muscle are produced. Still stronger solutions lead to a further slowing and relaxation, and very often a heart-block effect is noted, the auricle beating oftener than the ventricle in the ratio of 2 to 1,3 to 1 or even 4 to 1 . Finally the heart comes to a standstill in diastole. This peculiar heart-block action is very similar to that produced by the closely allied alkaloid narcotin, as described by the author elsewhere. ${ }^{12}$ Both Baxt and von Schroeder noted the toxic effect of large doses of papaverin on the frog's heart, but they failed to note the stimulating action of the drug when given in small doses (Fig. 1).

The stimulating action of papaverin on the heart is much better shown in mammalia and was studied by the author in the rabbit, cat and $\log$. This was done in part by perfusing excised hearts according to the methods of Martin or Langendorff, but was much more satisfactorily demonstrated by the study of the heart in situ with the chest opened, and the circulation intact. By the use of a cardiac plethysmograph or by direct myocardiographic tracings, it was found that small doses of papaverin produced a slight slowing of the heart beat and a marked increase in the tonicity of the heart muscles. The strength of the contractions and the volume output were also increased.

12. Macht: Am. Jour. Med. Sc., in press. 
That this cifect was not due to the action on the ardio-inhibitory conter. Wat hown by cutting the vagi. That it was not due to the antion of papaterin on the cranial anomomic nerve terminals in the heart. Was shown by administering atropin. which paralyzed the vagus cmelings. mut dicl mot change the effect of paparerin. That this actioni an the heart was not due to any effect on the cardio-idcelerator
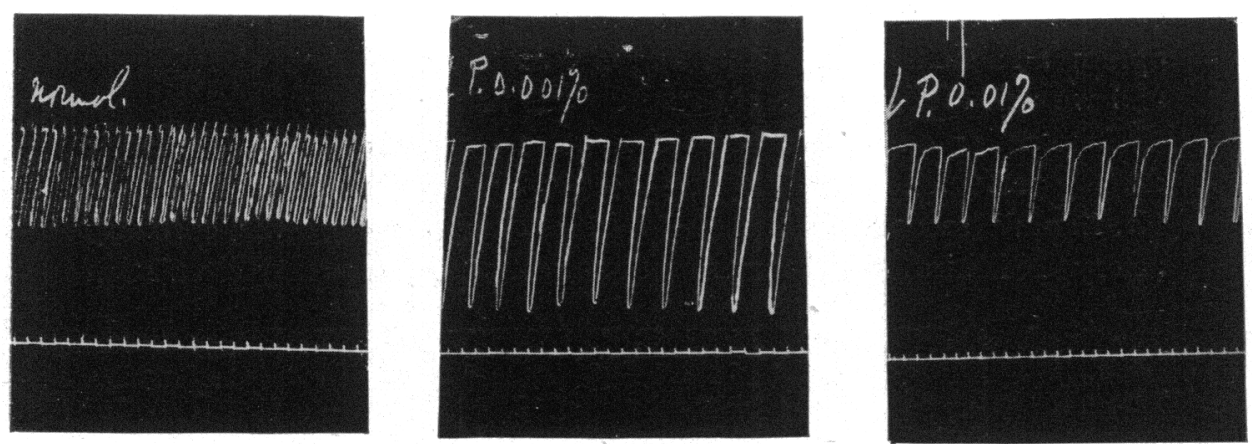

Fig. 1. Effect of papaterin on a frog's heart. The down stroke represents the ystole. Xine slowing and increased contraction ly a small dose 0.001

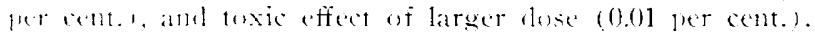

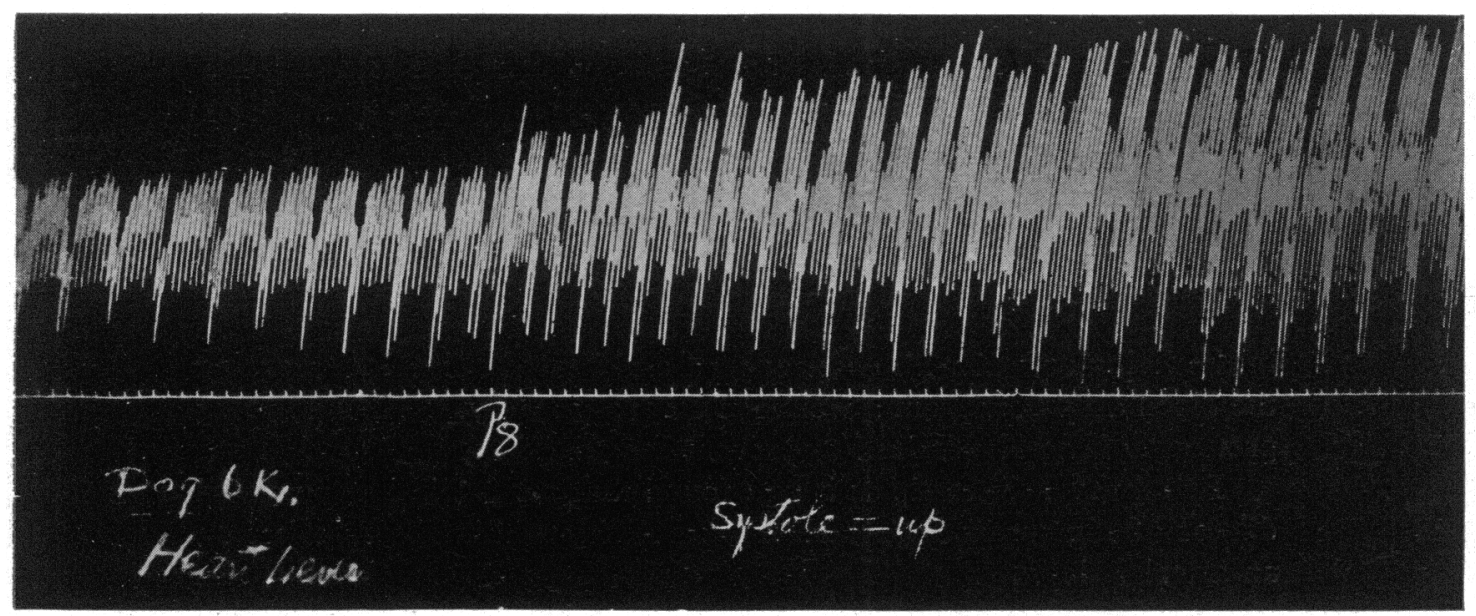

Fin. 2. Acton of papaverin on heart uf doge: myocardial tracing.

mechantism. Was shown by destroying the stellate ganglia. The stimulant elfect was found to be due to a distinct action on the heart muscle it -elf or the ganglia in it. This was proved bexperiments on decereliated atrimals. on special preparations acording to sherrington. ${ }^{13}$ and on excined frogse and terrapins" hearti f figst 2 and 31.

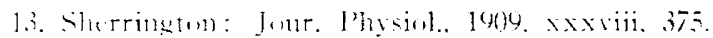


Large doses of papaverin had relatively the same effect on the mammalian heart as on the frog's heart. They produced excessive slowing and paralysis of the heart, at which stage the toxic effect on the central nervous system also generally manifested itself in the form of convulsions.

Closely associated with the action on the heart is the effect of papaverin on the coronary arteries and the coronary circulation. This effect has been treated fully in a study of the effect of the principal opium alkaloids on the coronary circulation, published elsewhere, " and we will therefore merely sum up our findings here.

The action on the coronary circulation was studied in three ways: first by perfusion of excised hearts, especially by the recent method of Krafkoff ; ${ }^{15}$ second, by the study of excised rings of the coronary artery, and third, by ascertaining the effect on the coronary circulation

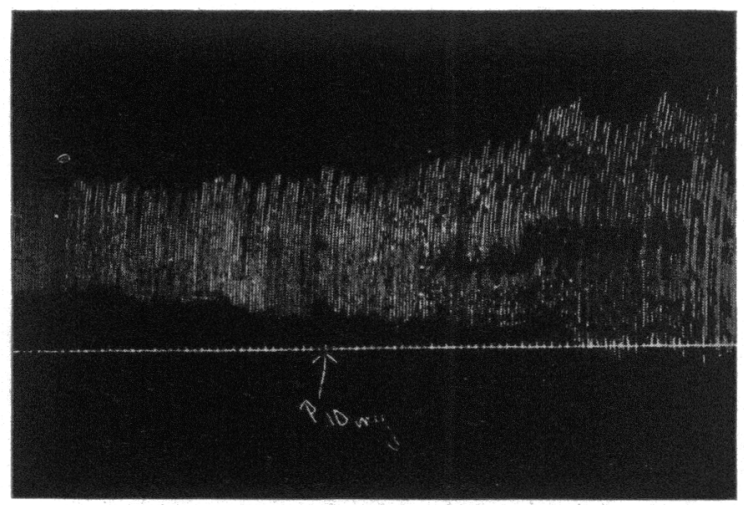

Fig. 3.-Action of papaverin on cat's heart. Heart is in a plethysmograph, the systole being represented by the down stroke.

in the living animal with chest opened and heart in situ, by recording the blood drop-flow from a wounded coronary artery, the blood having previously been hirudinized to prevent coagulation. ${ }^{16}$

By all the three methods it was found that papaverin is a powerful dilator of the coronary artery. Figure 4 shows this dilator effect on an arterial ring.

The following protocol illustrates the coronary dilatation as shown by Krakoff's method.

Expcriment 10.--.Perfusion of pig's heart by Krafkoff's method. The normal drop-flow was 25 drops per minute: after perfusion with 0.02 per cent. papaverin hydrochlorid solution the drop-flow was 46 drops per minute; five minutes later it became 56 drops per minute.

14. Macht: Jour. Am. Med. Assin., 1915, xliv, 1489.

15. Krafkoff : Arch. f. d. ges. Physiol. (Pflüger's), 1914, clvii. 501.

16. Bond: Jour. Exper. Med., 1910, xii, 575. 
Figure 5 illustrates the increase in coronary circulation as indicated by the increased number of the blood drops flowing from an incised coronary in a hirudinized cat.

The coronary ring method could be practiced on the human as well as other coronary arteries and it gave the same results.

IEffect on the Blood Pressure.-The effect of a drug on blood pressure is a resultant of its effect on the heart, on the vasomotor appara-

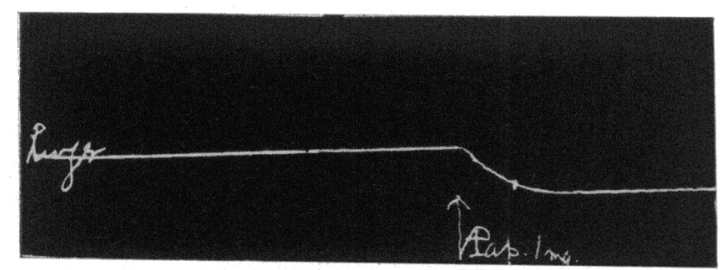

Fig. 4.--Action of papaterin on pig's coronary artery, three rings in chain; stretching weight $38 \mathrm{gm}$., lifting weight $18 \mathrm{gm}$. Note relaxation.
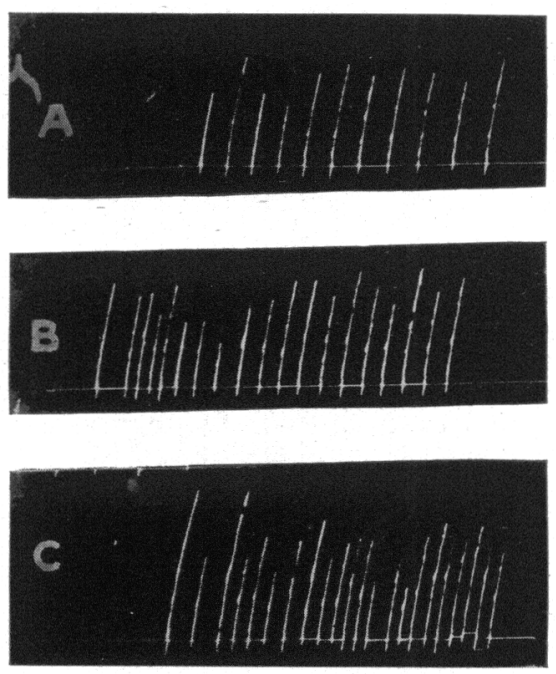

Fig. 5.-Experiment performed Dec. 22, 1914, on a cat of $2.5 \mathrm{~kg}$., under ether anesthesia, and hirudin 20 c.c. Study of blood-flow from wounded coronary artery by Bond's method $A$, normal drop-flow. 11 per minute; $B$, srop-flow after injection of $8 \mathrm{mg}$. papaverin hydrochlorich, 18 per minute; $C$, three minutes later, 26 per minute.

tus and on the ressels themselves. These factors should be borne in nind in studying the effect of paparerin on the blood pressure. The most striking effect of papaverin in any blood pressure experiment on a rabbit, at or dog-and the same is also true in man-is a fall in pressure. This fall in pressure was given after decerebrating the 


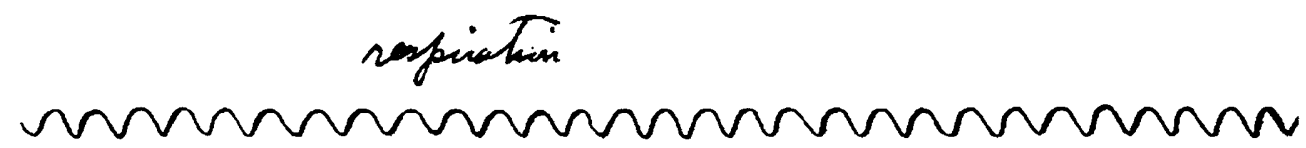

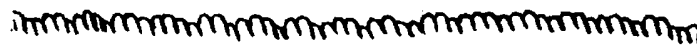

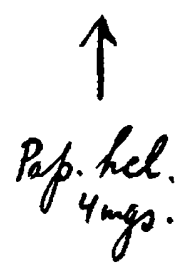

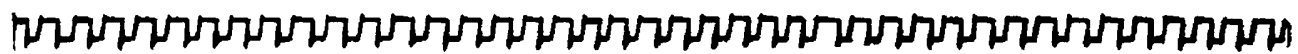
Time in sees.

Fig. 6.-Experiment performed January, 1915, on a cat of $2.5 \mathrm{~kg}$., ether anesthesia, showing effect of papaverin on blood pressure.
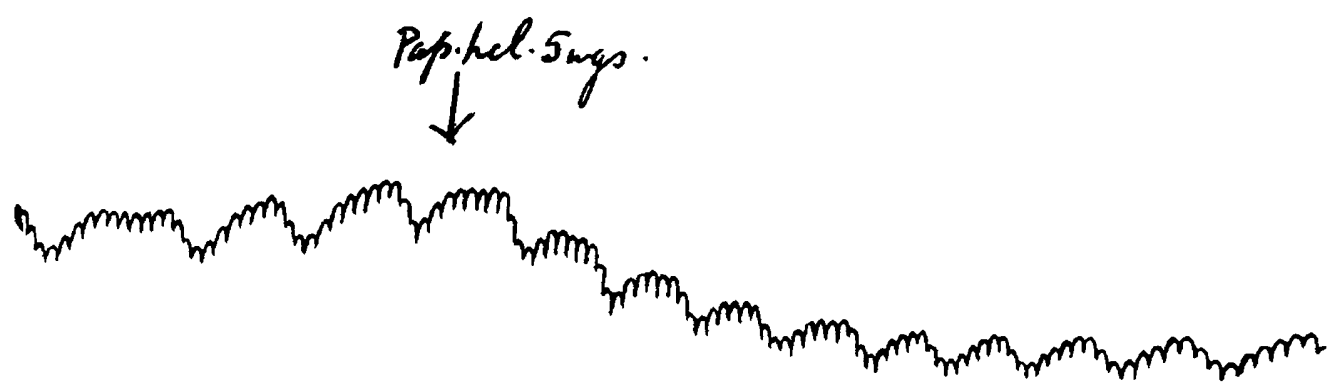

"

Fig. 7.-Experiment performed January, 1915, ether anesthesia, showing effect of papaverin on blood pressure with ragi cut. 
animal through the orbit and also in Sherrington's spinal preparations. It follows, therefore, that the alkaloid produces the fall in pressure chiefly through its peripheral effect on the vessel walls themselves. The following curves and protocols will illustrate the above points.

Protocol 1: Experiment was performed Oct. 29, 1914, on a cat of $4 \mathrm{~kg}$. Under ether anesthesia a spinal cord preparation, according to Sherrington, was made and curara administered. Normal blood pressure, $84 \mathrm{~mm}$.; normal pulse, 68 per 30 seconds. Papaverin hydrochlorid, $15 \mathrm{mg}$., was injected into femoral vein. One minute after, blood pressure was $64 \mathrm{~mm}$; ; pulse, 68 per 30 seconds.; five minutes after blood pressure was $70 \mathrm{~mm}$; pulse, 70 per 30 seconds.

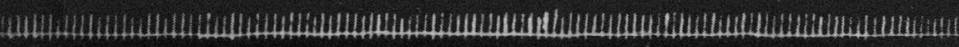
2100

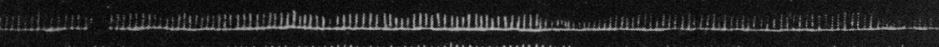

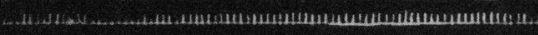

Fig. 8.-Perfusion of hind legs of Rana pipicns. Upper line gives number of drops on perfusing with normal saline; second line gives number of drops on perfusing with papaverin hydrochlorid, 0.01 per cent. solution in normal saline; lower line indicates time in seconds.

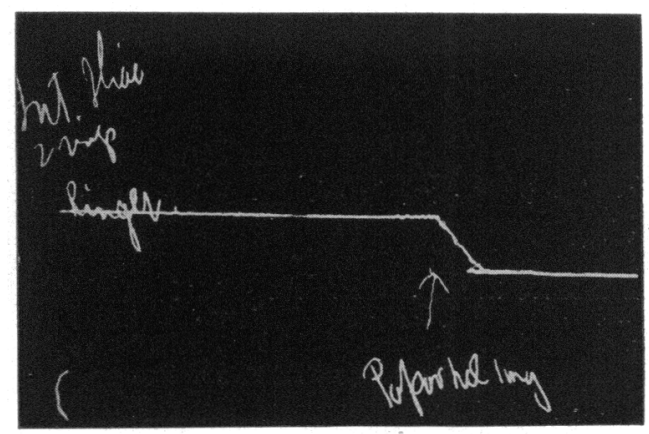

Fig 9.- Action of papaverin on internal iliac artery of pig. Two rings, stretching weight $30 \mathrm{gm}$., lifting weight $16 \mathrm{gm}$.

Protocol 2: Experiment was performed Jan. 8, 1915, on a cat of $2.5 \mathrm{~kg}$. Under ether anesthesia decerebration was performed through the orbit. The normal blood pressure was $72 \mathrm{~mm}$; pulse. 65 per 30 seconds. Papaverin hydrochlorid, $10 \mathrm{mg.}$. was injected into femoral vein. One minute after, blood pressure was $56 \mathrm{~mm}$; pulse, 66 per 30 seconds; five minutes after blood pressure was $66 \mathrm{~mm}$. ; pulse, 65 per 30 seconds.

Action on Blood Vesscls.-The vasolilating action as noted in the blood pressure experiments could be shown by other methods.

The effect on the frogs' blood ressels was shown by perfusion of the hind legs by Trendelenlunrg's method. The action on the mammalian vessels was sturlied by means of arterial rings or strips, 
described by the atthor elsewhere. ${ }^{17}$ By this method it was interesting to note that different vessels differed in their reaction to papaverin. Whereas the coronary arteries, the carotids and subclavians, and internal and external iliacs were markedly relaxed by the drug, the pulmonary artery was but slightly dilated and the uterine arteries still less so. The effect on the mesenteric and splanchnic ressels was studied by means of the plethysmograph. and as might have been expected from the marked fall noted in blood pressure experiments, they were greatly dilated. This is well illustrated by the figures.

summing up the circulatory effect of papaverin, we may therefore say that it causes a fall in blood pressure, which is due partly to its effect on the brain, but chiefly to its peripheral action; that it produces a nurlied vasodilatation, especially of the peripheral and splanchnic ressels: that it increases the coronary circulation, and that, in small

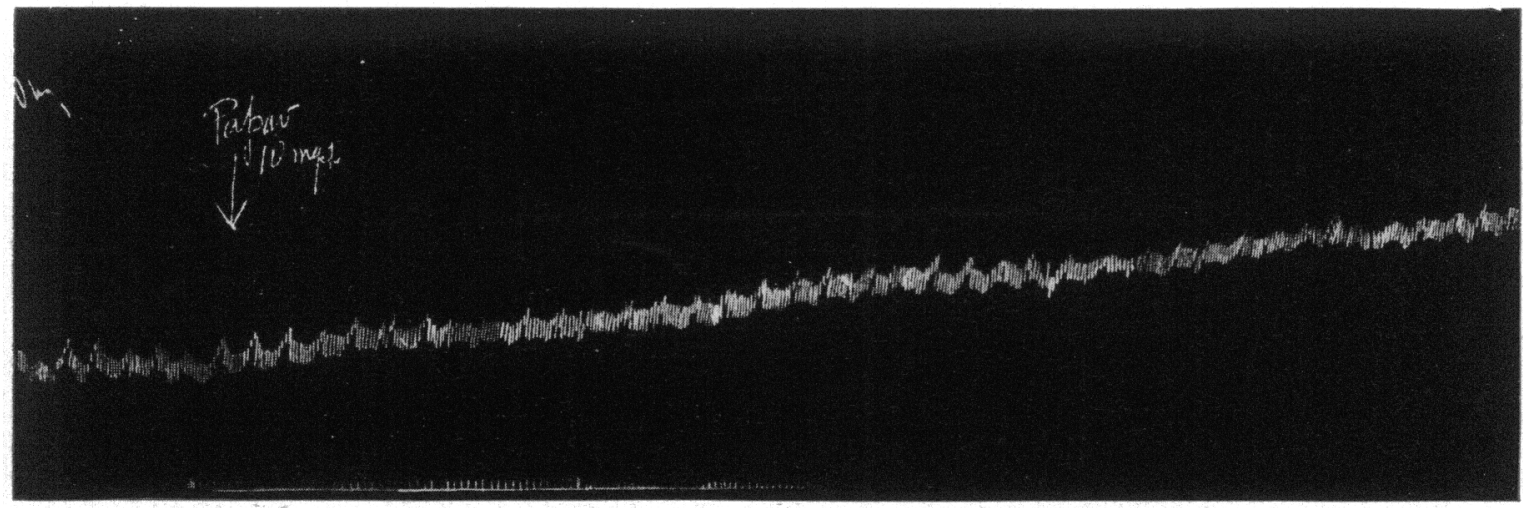

Fig. 10.--Effect of papaverin on intestinal vessels, as recorded by a plethysmograph. Curve upward indicates vasodilatation.

doses, it slows the heart, at the same time tending to increase the strength of its contractions.

\section{ACTION ON THE RESPIRATION}

The action of papaverin on the respiration has been touched upon by the author in another paper dealing with the action of opium alkaloids in general on the respiration. ${ }^{1 *}$ There it was pointed out that the pharmacologic study of the respiration is a complex matter. It is not sufficient merely to determine the rate and volume output of respiration. Drugs may affect the respiratory function in several ways: by acting upon the respiratory center directly; by producing changes in metabolism; by altering the mechanical conditions of the

17. Macht: Jour. Pharmacol. and Exper. Therap., 1914, vi, 13.

18. Macht: Jour. Pharmacol. and Exper. Therap.. 1915, vii, 339. 
chest and abdomen: by acting on the bronchoconstrictors or bronchodilators: and indirectly by changes in the cercbral circulation, etc. Accordingly, in studying the action of papaverin on the respiration, observations were made on the rate of respiration, the total volume of air respired per minute or total icntilation, the true or alicolar ientilation. the effect on the respiratory center, and the effect on the bronchi. By the method lescribed in the paper referred to, it was found that papaverin, while producing a slight narcotic effect wpon the animal, exerts a distinctly stimulating effect on the respiration. While the rate of respiration is slightly decreased, the volune output and

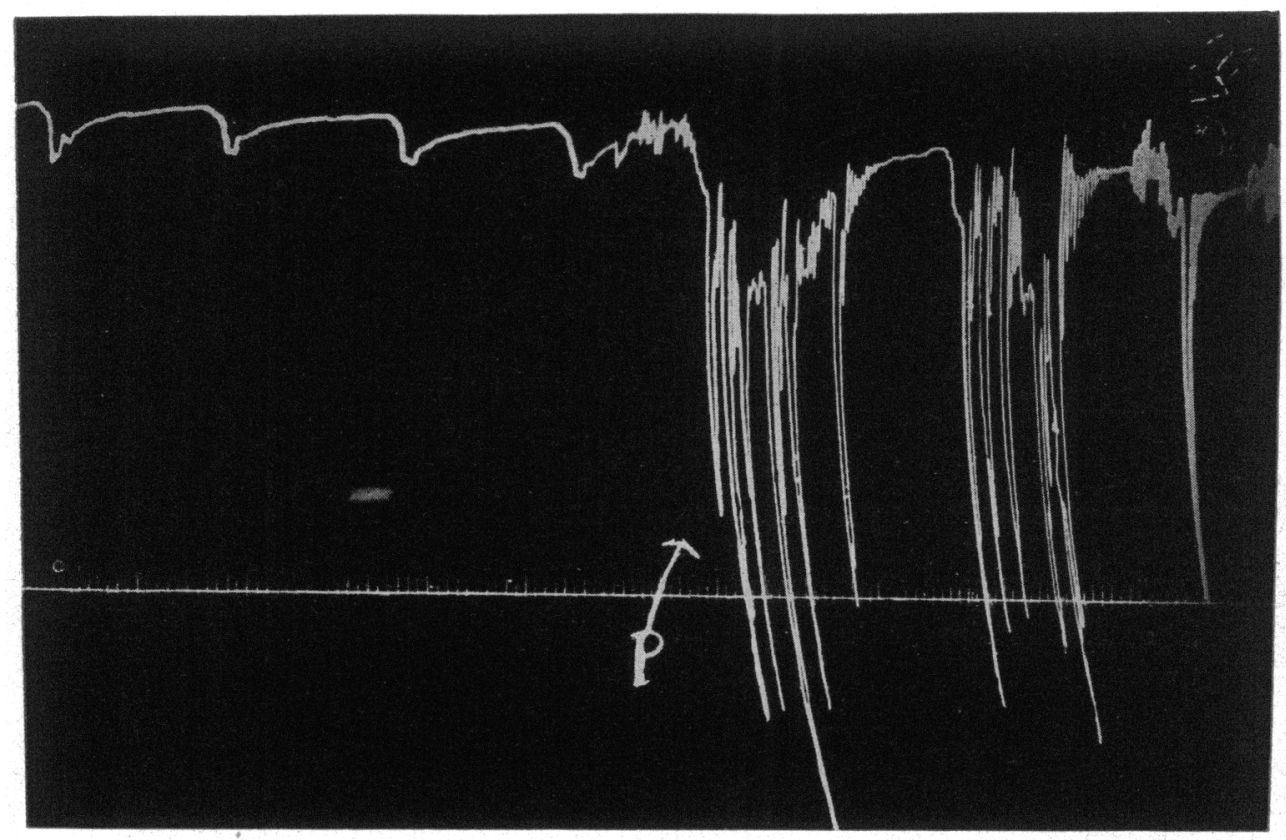

Fig. 11.-Experiment performed April 27. 1915. Perfusion of respiratory center by Hooker's method in a dog weighing $7.5 \mathrm{~kg}$. At $l^{\prime} 2 \mathrm{mg}$. of papaverin hycirochlorid were introduced. Note stimulation of center.

alveolar ventitation are markedly increased. The respiratory center is quite active as shown by its lively response to carbon dioxid inhalations, and the lead space is greatly enlarged, indicating a bronchodilatation. The bronchodilator effect was also proved directly by experiments with bronchial rings. The stimulating action of papaverin on the center was furthermore corroborated directly by perfusion of the medulla by llooker's method.

The fullowing protocols illustrate the above findings, and Figure 11 shows the result of a papaverin experiment on the medulla. 
Experiment was performed Feb. 24, 1915, on a rabbit of $1,150 \mathrm{gm} . ; 11$ a. m., rabbit tied down and allowed to get quiet.

$\begin{array}{ccccc}\text { Time } & \begin{array}{c}\text { Rate per } \\ \text { Bin. }\end{array} & \begin{array}{c}\text { Vol. per } \\ \text { min., c.c. }\end{array} & \begin{array}{c}\text { Vol. per } \\ \text { resp., c.c. }\end{array} \\ \begin{array}{ccc}\text { Air of room } \\ \mathrm{CO}_{2} 5 \%\end{array} & 68 & 450 & 6.6 \\ \mathrm{CO}_{2} 10 \% & 68 & 540 & 7.9 \\ & & 68 & 640 & 9.4\end{array}$

11:50 a. m., injected subcutaneously papaverin hydrochlorid, $8 \mathrm{mg}$.

\begin{tabular}{|c|c|c|c|c|}
\hline Time & Breathing & $\begin{array}{l}\text { Rate per } \\
\text { min. }\end{array}$ & $\begin{array}{l}\text { Vol.per } \\
\text { min., c.c. }\end{array}$ & $\begin{array}{l}\text { Vol. per } \\
\text { resp., c.c. }\end{array}$ \\
\hline $12: 15$ p. m.. & $\begin{array}{c}\text { Air of room } \\
\mathrm{CO}_{2} 5 \% \\
\mathrm{CO}_{2} 10 \%\end{array}$ & $\begin{array}{l}60 \\
64 \\
66\end{array}$ & $\begin{array}{l}480 \\
520 \\
660\end{array}$ & $\begin{array}{r}8.0 \\
8.1 \\
10.0\end{array}$ \\
\hline $1: 30$ p. m... & $\begin{array}{c}\mathrm{Air} \text { of room } \\
\mathrm{CO}_{2} 5 \% \\
\mathrm{CO}_{2} \quad 10 \%\end{array}$ & $\begin{array}{l}54 \\
60 \\
60\end{array}$ & $\begin{array}{l}470 \\
520 \\
800\end{array}$ & $\begin{array}{r}8.7 \\
8.7 \\
13.3\end{array}$ \\
\hline $2: 30$ p. m........... & $\begin{array}{lr}\mathrm{CO}_{2} & 5 \% \\
\mathrm{CO}_{2} & 10 \%\end{array}$ & $\begin{array}{l}58 \\
60\end{array}$ & $\begin{array}{l}500 \\
800\end{array}$ & $\begin{array}{r}8.6 \\
13.3\end{array}$ \\
\hline
\end{tabular}

Experiment was performed March 11, 1915, on a rabbit of $910 \mathrm{gm}$.

2:00 p. m., animal tied down and allowed to quiet itself.

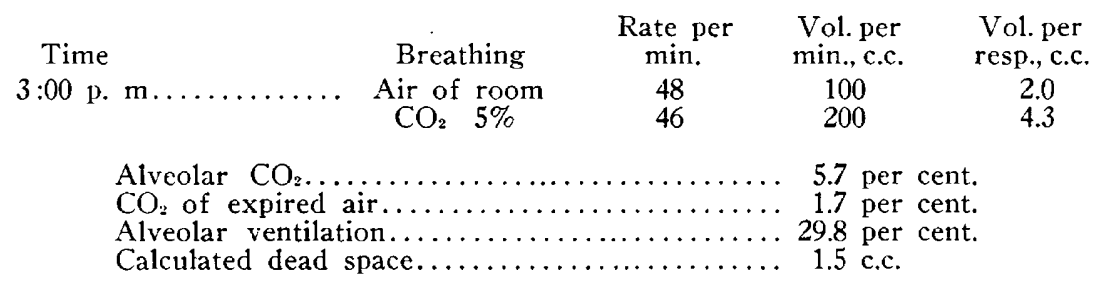

3:35 p. m., injected subcutaneously papaverin hydrochlorid, $3 \mathrm{mg}$.

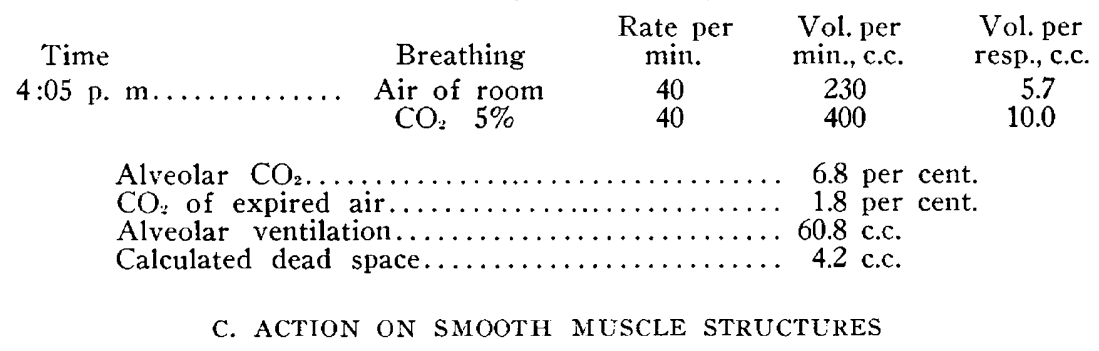

Attention to this remarkable property of papaverin has been called by Pal, to whom we are indebted for arousing interest in the subject. Pal mitle a broad generalization to the effect that the alkaloid lowered the tonus and produced relaxation of all smooth muscle structures, without paralyzing them.

This generalization seems to have been based chiefly on Pal's clinjcal experiences, as his published experimental work is confined chiefly to studies of intestinal muscle. It is remarkable, however, to find that later observations by other investigators and the experimental work of the present author all seem to confirm fully the truth of Pal's 
stacment. The present atuhur stulied the ation of papaterin on all

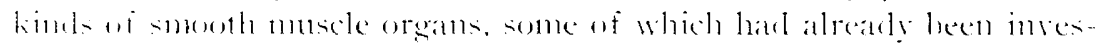

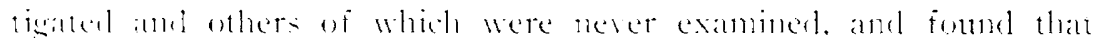

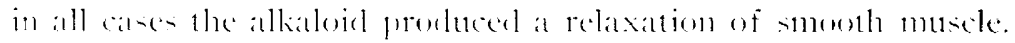

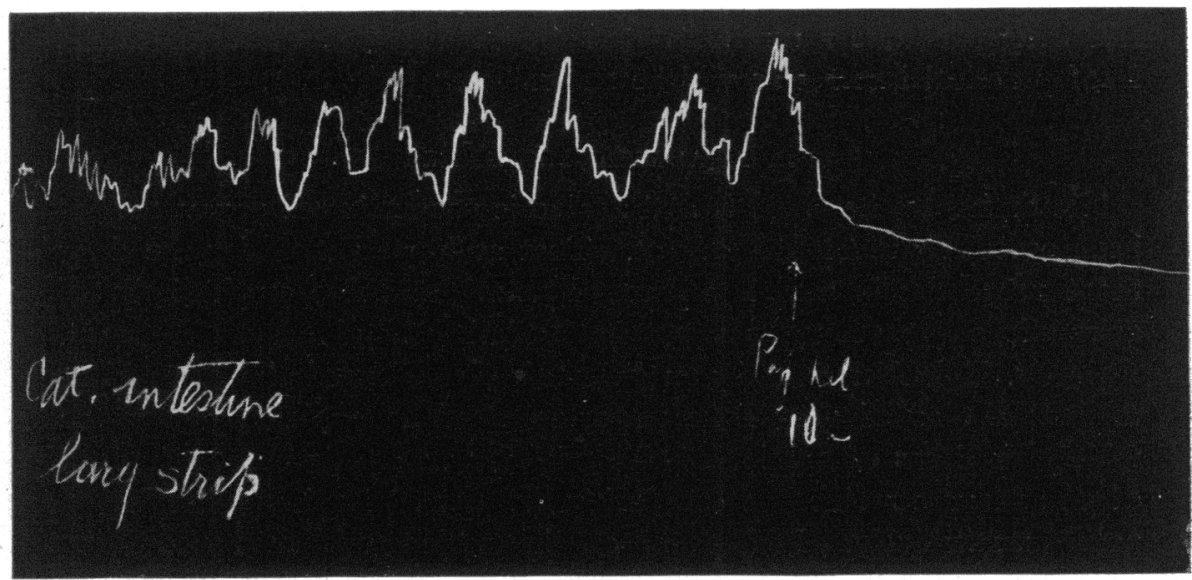

1.iv. 12. Aetion of paparerin on Longitulinal muscle of cat's intestine.

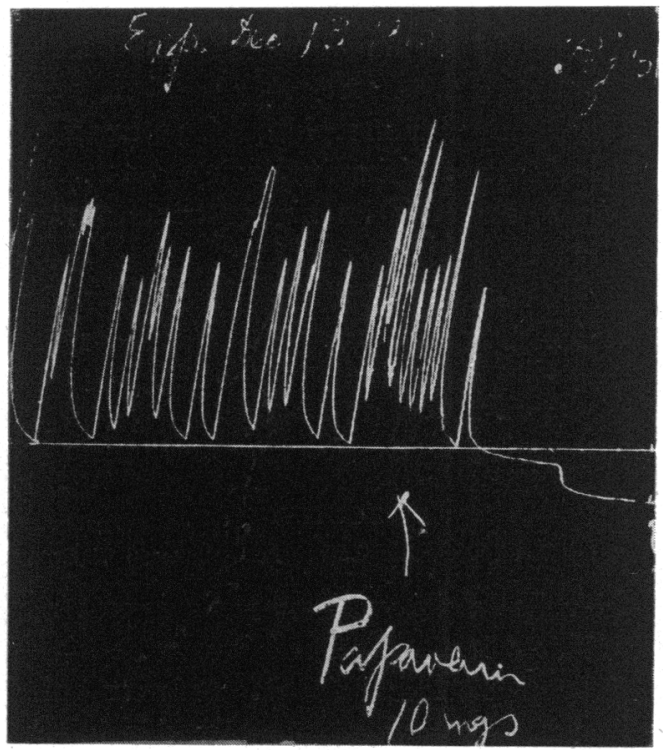

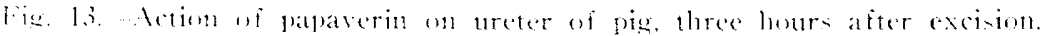
cimarl streke indianes the contration.

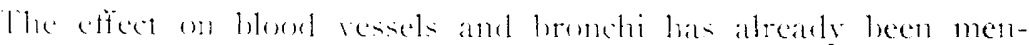

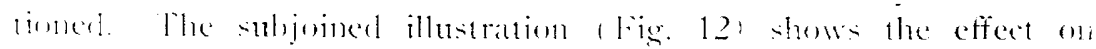

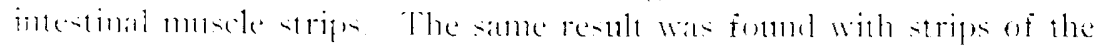


uterus and the bladder. In experiments on excised pyloric sphincters the present author could confirm the clinical experiences of $\mathrm{Pal}$ in pylorospasm. A relaxation of the sphincter was noted. Furthermore, one of the most interesting effects of papaverin to be mentioned in this place is its effect on the ureter. The present author found that this drug produces a marked relaxation of that organ and this effect is of practical interest as will be shown later (Fig. 13).

\section{ANALGESIC PROPERTIES}

Attention to the narcotic and analgesic properties of papaverin has been especially directed by Baxt. That author claimed for the drug these properties in a high degree. Fronmüller ${ }^{19}$ also emphasized the analgesic effect of papaverin. On the other hand Claude Bernard, Sichting, Eulenburg ${ }^{20}$ and von Schroeder, considered the alkaloid in this respect as of very little importance. The explanation for the wide differences of opinion on the subject was chiefly due to the lack of an adequate method of comparing the effect of opium alkaloids on pain quantitatively. In a paper on the subject published elsewhere, the present author elaborated a simple method for a quantitative study of pain stimuli on the surface of the body, and the effect of papaverin was investigated in that connection. ${ }^{* 1}$

It was found that papaverin possesses analgesic properties in a higher degree than codein, the effect of $40 \mathrm{mg}$. being not much inferior to that produced by $10 \mathrm{mg}$. of morphin. The onset of the analgesia, however, was much slower and its duration shorter. The general narcotic effect and depression of the higher centers was, on the other hand, much less than that from morphin.

Observations were made on six normal individuals, and the results, barring slight individual variations, agreed in all cases. The following protocols will serve as illustrations. It will be noted that injections of papaverin are slightly painful at the site of injection, but this discomfort soon passes away.

\section{E. TOXICITY}

Before discussing the therapeutic applicability of papaverin, it is essential to consider its toxicity. Papaverin is not a very poisonous drug and comparatively large doses of it can be given without dangerous results. Indeed the lethal dose for higher animals is so large that for economic reasons it was not deemed profitable to push the drug till death was produced in too many experiments. It was suffi-

19. Fronmüller: Klinische Studien über narkotische Arzneimittel, Erlangen, 1869.

20. Eulenburg: Die Hypodermotische Injection der Arzneimittel, Berlin, 1867.

21. Macht, Herman, and Levy: Jour. Pharmacol. and Exper. Therap., 1916, viii, 1 . 

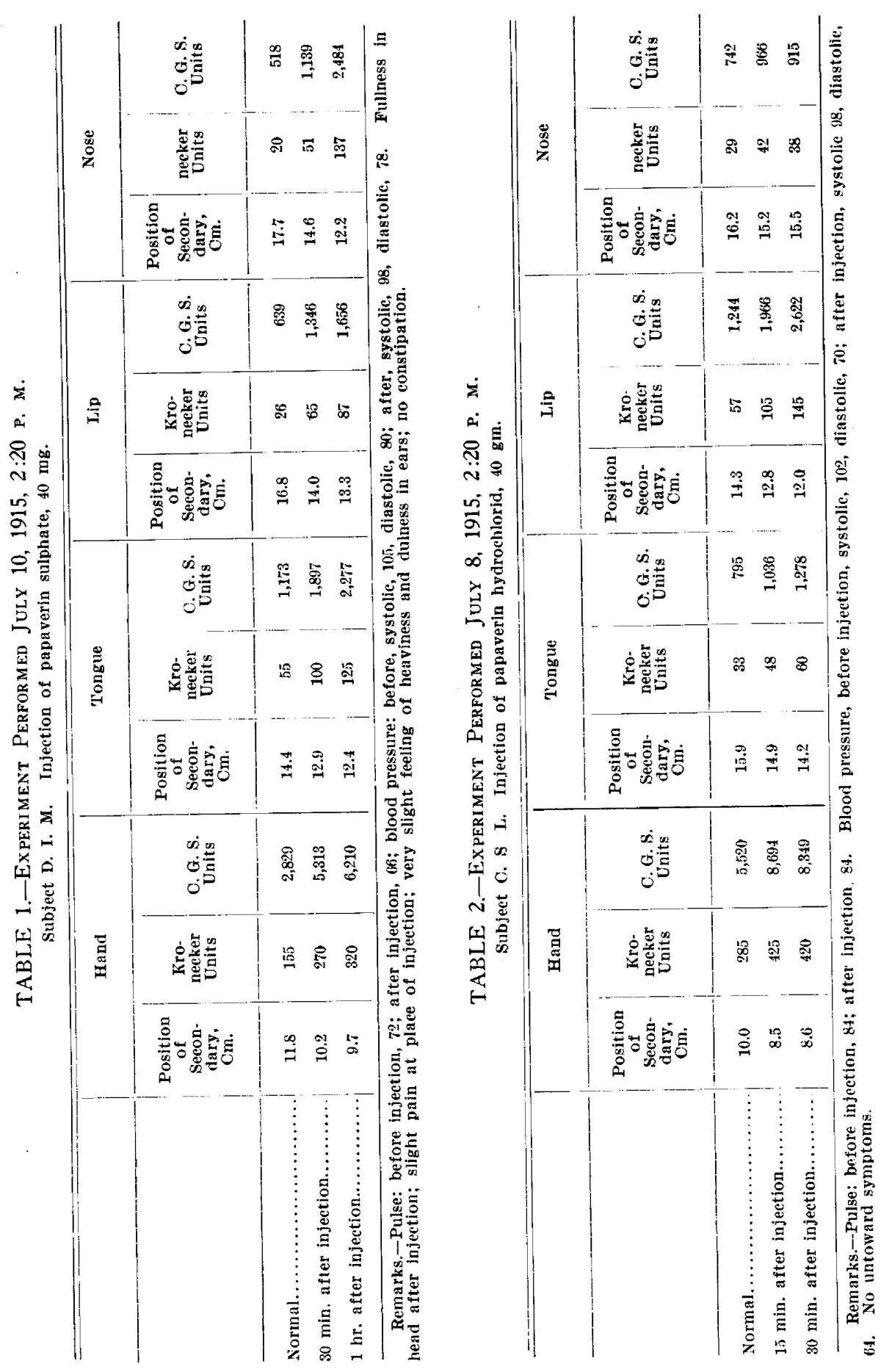


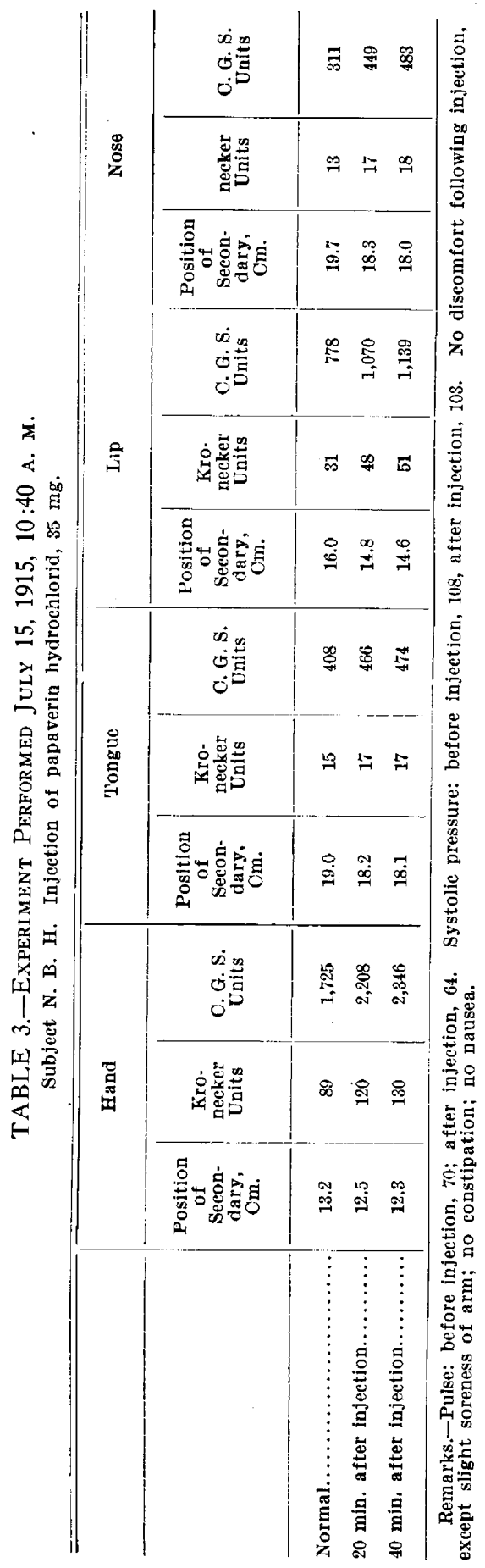

Downloaded From: http://archinte.jamanetwork.com/ by a Monash University Library User on 06/17/2015 
cient for all practical purposes to ascertain the quantity of the drug which produced toxic symptoms.

In the frog it was found that the minimal lethal dose was about $1 \mathrm{mg}$. per gram weight of frog. These results agreed well with those of von Schroeder.

In the guinea-pig $100 \mathrm{mg}$. administered subcutaneously stimulated respiration; $200 \mathrm{mg}$. produced violent convulsions, and death in about ten minutes. A similar experience with guinea-pigs is reported by Bradbury. ${ }^{22}$

White mice required about $0.5 \mathrm{mg}$. per gram weight to produce convulsions and death in half an hour.

In rats, according to Bradbury, $300 \mathrm{mg}$. produced weakness of the muscles, but no death.

In the case of rabbits different experimenters show considerable variations in their figures. According to Bradbury it required $480 \mathrm{mg}$. to produce death. Kunkel ${ }^{23}$ claims that doses up to $1 \mathrm{gm}$. produce muscular weakness, and larger doses produce convulsions and death, but he does not state whether the drug was given by stomach or by injection. Lewin ${ }^{24}$ gives $2 \mathrm{gm}$. as the lethal dose by mouth. In the present author's experiments the drug was not pushed to a lethal outcome; but it was found that doses of $25 \mathrm{mg}$. per kilo, subcutaneously, excited the animal, but did not cause death, while repeated doses of $10 \mathrm{mg}$. each, every five to ten minutes, intravenously, caused convulsions, after five or six doses.

In cats the present author found that $55 \mathrm{mg}$. per kilogram, subcutaneously, produced no untoward symptoms. Repeated intravenous in jections of $10 \mathrm{mg}$. doses in cats of 2.5 to $3 \mathrm{~kg}$. produced convulsions after six doses.

In dogs Baxt noted marked anesthesia after $100 \mathrm{mg}$. In the present author's experience subcutaneous injections of $50 \mathrm{mg}$. per kilogram produced distinct narcosis with uneventful recovery. Intravenous injections in doses of $10 \mathrm{mg}$. every five minutes produced convulsions in a $\mathrm{dog}$ of $6 \mathrm{~kg}$. after about $100 \mathrm{mg}$. were injected.

In reference to the safe dosage for man, we have collected considerable data. Schroff and Hoffman ${ }^{25}$ state that doses of $450 \mathrm{mg}$. produce no effect. Fronmüller injected subcutaneously $240 \mathrm{mg}$. without harmful results. Leidesdorff ${ }^{26}$ injected insane patients with doses of over $400 \mathrm{mg}$. without danger. Blyth ${ }^{2 \tau}$ puts $1 \mathrm{gm}$. as the dosage

22. Bradbury: Lancet, London, July, 1899.

23. Kunkel: Toxikologie, 1901, ii, 820.

24. Lewin: Toxikologie, Berlin, 1897, p. 260.

25. Schroff and Hoffman: Wien. med. Wchnschr., 1868, pp. 935 and 952.

26. Leidesdorff: Ztschr. d. Wien. Aerzte, 1868, xiii, 115.

27. Blyth: Poisons, London, 1906, p. 322. 
limit, and Pal quotes Bouchut also as giving quantities up to $1 \mathrm{gm}$. subcutaneously. These doses, however, are certainly not to be considered safe at present, and Lewin cites a case with some weakness produced by $180 \mathrm{mg}$. Pal recommends 40 to $80 \mathrm{mg}$. subcutaneously as perfectly safe doses, and states that higher doses also produce no harmful results The author's experience with the drug on himself, colleagues and patients certainly agrees with Pal's, so that doses of from $40 \mathrm{mg}$. to $80 \mathrm{mg}$. subcutaneously, in adults, may certainly be administered without trepidation.

The present author injected papaverin intravenously on three occasions without any untoward symptoms. It was found that $40 \mathrm{mg}$. well diluted with 200 c.c. of saline and injected slowly could be administered safely.

No cumulative action from papaverin has been noted by the author. Repeated intravenous injections of from 10 to $20 \mathrm{mg}$. of the hydrochlorid daily over periods of from two to three weeks showed no such effect in rabbits or dogs. Papaverin is for the most part unchanged in the body, and is excreted chiefly through the urine, bile, and partly throught the small intestine. *

\section{Clinical Experiences}

The clinical application of papaverin should of course follow its physiological behavior. This has been done, in a measure, by Pal and his school. Thus its peculiar effect on the circulation, promoting the coronary circulation, lowering the pressure and stimulating the heart, will suggest its use in angina pectoris and in cases with hypertension. Pal actually employed it in aborting uremic crises. ${ }^{29}$

Its stimulating effect on the respiratory center would suggest its use in cases where depression of that center is undesirable.

Its analgesic action would suggest its use as a substitute for morphin, especially where codein is not effective.

Lastly, its peculiar action on smooth muscle would indicate its use in all cases with visceral spasm.

In the present communication, the author is reporting his rather limited experience with the drug, not so much as a positive proof of the therapeutic value of papaverin, as in order to stimulate further observation. The following cases were selected more or less at random, and papaverin was administered in some cases to relieve pain and in others for the purpose of exhibiting its other properties. The results seem to be encouraging.

On examining the histories, one will note that in regard to its pain-relieving quality papaverin, though inferior to morphin, is cer-

* Dragendorff: Ermittelung von Giften, 1895, p. 225.

28. Bouchut: Cited by Pal in Med. Klin., Nov. 2, 1913, No. 44.

29. Pal: Med. Klin., Nov. 2, 1913, No. 44. 
tainly equally as efficient as, and even more efficient than, codein. It will also be noted that it was more or less efficient in the cardiac cases (Cases 14, 15, 22, 27, 28, 30). In the respiratory conditions the effect was not so marked, but attention is called to Case 5 , in which it was efficacious in relieving the troublesome cough of an advanced consumptive, who was habituated to heroin; and its really striking relief of the cough in the case of aneurysm, No. 7, which was not relieved by any other drug.

The employment of papaverin in bronchial asthma was recommended by Pal. In Case 10, the effect of papaverin on bronchial asthma in a boy of 15 years was immediate. Case 11 , however, another case diagnosed as "asthma," was not relieved; but neither was that patient relieved by epinephrin or atropin.

Cases 13 and 25 illustrate the effect of papaverin in relaxing the spasm of biliary ducts, and other successful examples of the antispasmodic properties of the drug are found in Cases 12, 17, 18, and 21.

The peculiar property of papaverin in relaxing the tonus and contractions of smooth muscle organs led $\mathrm{Pal}$ to recommend it in cases of pylorospasm. Its value in such cases was demonstrated by Holzknecht and Sgalitzer ${ }^{30}$ through their Roentgen-ray studies, and it has recently been further recommended by Delprat. ${ }^{31}$ All these authors administered papaverin by hypodermic injection. Inasmuch as a very striking effect is produced by the drug on smooth muscle in vitro, and that by very small doses, as shown by Popper, ${ }^{32}$ it occurred to the present author that papaverin might in such cases be advantageously given by mouth, and in fact two or three cases of pylorospasm treated in this way in the Harriet Lane Home for Invalid Children (Professor Howland) gave favorable results.

Another application of the tonus-relaxing quality of papaverin suggested by the present author was its introduction directly into the ureter through a cystoscope, in cases of ureteral calculus and colic. Observations along this line are being carried on at the James Buchanan Brady Urological Institute (Professor Young). It may be here stated that two cases of ureteral stone were successfully treated by Dr. T. I. Gerathy in this way. ${ }^{33}$

\section{SYNOPSIS OF CLINICAL CASES}

CASE 1.-S. M., dispensary case, F. 39372. Acute gastric indigestion. Forty mg. hypodermically. Slight relief.

CASE 2.-M. G., dispensary case, E. 91401. Severe cramps in one leg. Tablets $40 \mathrm{mg}$. each, three times a day by mouth. Distinct relief.

30. Holzknecht and Sgalitzer: Munch. med. Wchnschr., 1913, No. 3.

31. Delprat: Nederl. Tijdschr. v. Geneesk., 1915, ii, 1311.

32. Popper: Arch. f. d. ges. Physiol. (Pflüger's), 1913, cliii.

33. Gerathy and Macht: Bull. Johns Hopkins Hosp., 1916, xxvii, 119. 
CaSe 3.-A. C., dispensary case, F. 33848. Very persistent cough; tuberculosis. Tablets $40 \mathrm{mg}$. each, three times a day. Slight relief.

CASE 4.-J. Y., dispensary case, F. 36190 . Chronic bronchitis and emphysema; persistent cough. Tablets $40 \mathrm{mg}$. each, three times a day. No relief.

CASE 5.-P. R., outside case, white woman, 23 years of age. Advanced tuberculosis. Codein has no effect. Dionin and heroin have very little effect because of habitual use for cough. Tablets of papaverin, $40 \mathrm{mg}$. each, patient says relieved her a little more than heroin.

CASE 6.-H. M., dispensary case, E. 58406. Tuberculous laryngitis and phthisis. Marked relief of cough and pain from tablets of papaverin hydrochlorid, $40 \mathrm{mg}$.

CASE 7.-J. B., dispensary case, F. 38599. Aortic aneurysm; troublesome cough. Patient tried morphin, heroin, codein, narcophin. Finds that papaverin tablets, $40 \mathrm{mg}$. each, relieve better than any other drug. Same experience repeatedly.

CASE 8.-W. D., dispensary case, E. 59866. White man, 36 years of age. Lumbago. Relieved by injecting $40 \mathrm{mg}$. of papaverin sulphate. Pulse before injection 72, after injection 68 per minute.

CASE 9.-S. G., outside case. White man, 35 years of age. Acute gastric indigestion. Injection of $40 \mathrm{mg}$. papaverin sulphate with slight relief. Pulse Defore injection 88 , after injection 72 per minute.

CASE 10.-B. H., outside case. White boy, 15 years of age. Bronchial asthma. Injection of $30 \mathrm{mg}$. papaverin sulphate. Immediate relief.

CASE 11.-Dr. L. Karlinski's case. White woman. "Asthma." Papaverin injection does not relieve. Epinephrin injection gives no relief, but aggravates condition. Only drug giving any relief is morphin.

CASE 12.-R. A., outside case. White woman, 26 years of age. Uterine colic. Relieved by injection of $40 \mathrm{mg}$. papaverin sulphate.

CASE 13.-R. S., dispensary case, F. 30928. White woman, 32 years of age. Gallstone colic. Two attacks, at different times, promptly relieved by injections of $40 \mathrm{mg}$. papaverin sulphate. A third time patient had attack at home, and called a physician, who gave her an injection of morphin. Patient was made "sleepy," but relief was not as prompt as from papaverin.

CASE 14.-M. E., outside case. White man, 46 years of age. Myocardial insufficiency. Dyspnea and precordial pain relieved temporarily by injection of $40 \mathrm{mg}$. papaverin sulphate.

CAse 15.-M. B., outside case. White woman, 64 years of age. Anginal pains and dyspnea from myocardial and arteriosclerotic changes. Relieved temporarily by injection of $40 \mathrm{mg}$. papaverin sulphate. Pulse distinctly fuller and pressure lower after injection.

CASE 16.-M. H., outside case. White woman, 26 years of age. Acute neuritis of right hand and forearm. No relief from papaverin injection of $40 \mathrm{mg}$.

CASE 17.-Dr. F. P., 56 years of age. Renal colic; very severe, requiring chloroform inhalations and morphin. Slight relief experienced for an hour or two after injection of $40 \mathrm{mg}$. papaverin sulphate.

CASE 18.--R. G., dispensary case, F. 23824. White mall, 32 years of age. Lead colic. Distinct relief from injection of $40 \mathrm{mg}$. papaverin sulphate. Pulse before injection 80 , after injection 72 per minute.

CASE 19.--N. J., outside case. Man, black, 40 years of age. Acute enteritis. Pain was relieved by injecting $40 \mathrm{mg}$. of papaverin sulphate. He came next day asking for another injection.

CASE 20.-M. K., outside case. White woman, 38 years of age. Severe nervous headache, relieved by injecting $40 \mathrm{mg}$. of papaverin sulphate.

CASE 21.-M. K., outside case. White woman, 30 years of age. Acute vesical spasm. Pain relieved very quickly by injection of $40 \mathrm{mg}$. of papaverin sulphate. 
CASE 22.-M. B., outside case. White man, 56 years of age. Anginoid attacks. Relieved by $40 \mathrm{mg}$. of papaverin hydrochlorid in solution by mouth every four hours.

CASE 23.-M. S., outside case. White man, 60 years of age. Cardiac dyspnea, very bad. Very little relief from injection of $40 \mathrm{mg}$ papaverin.

CASE 24.-J. W., Ward F. (care of Dr. F. A. Evans). Hysteria. Injection of $40 \mathrm{mg}$. papaverin sulphate for nervousness and insomnia; not efficacious.

CASE 25.-S. W., Ward O (care of Dr. F. A. Evans). Hyperacidity and gallstones (?). Injection of $40 \mathrm{mg}$. papaverin sulphate for a paroxysm of pain brought about complete relief in fifteen minutes. Before injection respiration 24 , pulse 84 , blood pressure, systolic 165 , diastolic 95 ; after injection respiration 26, pulse 70, blood pressure, systolic 140, diastolic 90 .

CASE 26. -J. W., Ward F (care of Dr. F. A. Evans). Psychasthenia malignum; hysteria. Injection of $40 \mathrm{mg}$. papaverin sulphate for nervousness and insomnia proved efficacious; slept all night. Before injection respiration 24, pulse 88; half hour after injection respiration 24 , pulse 84 .

CASE 27.-A. B., Ward F (care of Dr. F. A. Evans). Syphilis of aorta; aortic insufficiency; myocardial insufficiency. Injection of $40 \mathrm{mg}$. papaverin sulphate for dyspnea and restlessness. Quieted a little after administration; slept brokenly several hours. Before injection respiration 30, pulse 80; half hour after injection respiration 30 , pulse 80 .

CASE 28.-E. M., Ward F (care of Dr. F. A. Evans). Hypertension; myocardial failure. Injection of $40 \mathrm{mg}$. papaverin sulphate for dyspnea and restlessness. Quite efficacious; patient almost asleep in ten minutes. Before injection respiration 32 , pulse 94 , blood pressure, systolic 185 , diastolic 100 ; after injection respiration 26, pulse 93 , blood pressure, systolic 185 , diastolic 95 .

CASE 29.-T. H., Ward F (care of Dr. F. A. Evans). Lobar pneumonia; pericarditis. Injection of $40 \mathrm{mg}$. papaverin sulphate not efficacious in relieving pleural pain. Neither is relief given by injection of $1 / 6$ grain morphin.

CASE 30.-J. D., Ward F (care of Dr. F. A. Evans). Aortic insufficiency; bronchopneumonia. Injected $40 \mathrm{mg}$. papaverin sulphate for relief of cough, dyspnea and restlessness. Quite efficacious, asleep in thirty-five minutes and slept five hours. Before injection respiration 28, pulse 100; after injection respiration 24, pulse 98 .

CASE 31.-G. G., Ward F (care of Dr. F. A. Evans). Pneumonia; pneumothorax. Injected $40 \mathrm{mg}$. papaverin sulphate to induce quiet sleep. Not asleep in half hour, but quiet and drowsy. Before injection respiration 30, pulse 128; after injection respiration 30 , pulse 112 .

CASE 32.-R. A., Ward O (care of Dr. F. A. Evans). Bronchopneumonia. Injection of papaverin sulphate for dyspnea and restlessness. Not efficacious; some infiltration at site of injection next day.

\section{SUMMARY}

From the above data, it will be seen that the alkaloid papaverin exhibits certain very interesting pharmacologic properties. Chief among these are its effect on the heart and blood pressure, its action on the coronary circulation, its stimulating effect on the respiration, its relaxing and tonus-lowering influence on the smooth muscle structures, and its considerable analgesic power.

'These, together with its comparatively low toxicity, suggested its employment for therapeutic purposes. The clinical experiences described speak in its favor, and it is hoped that further observations may be made to determine its exact therapeutic value in medicine. 